\title{
Study on Anatomical Variations of Popliteal Artery and its Branches
}

\author{
Reema Kanchan Khalkho ${ }^{\circledR 1}$, A. K. Dubey ${ }^{\circledR 2}$, Renu Prasad ${ }^{\circledR 3}$, Prabhat Kumar Lal ${ }^{\circledR 4}$ \\ ${ }^{1}$ Tutor, Department of Anatomy, RIMS, Ranchi, Jharkhand, India, ${ }^{2}$ Professor \& Head, Department of Anatomy, RIMS, Ranchi, Jharkhand, India, ${ }^{3}$ Ex-Professor, \\ Department of Anatomy, RIMS, Ranchi, Jharkhand, India, ${ }^{4}$ Associate Professor, Department of PSM, Darbhanga Medical College, Darbhanga, Bihar, India.
}

\section{Abstract}

Introduction: Variations in branching of popliteal artery is important for the orthopaedicians, vascular surgeons and radiologists. The present study was conducted to assess the anatomical variations in popliteal artery, its terminal branching pattern. Subjects and Methods: The present cross-sectional study included 72 lower limbs received for cadaveric dissection. Anatomical variations of the popliteal artery were noted. Results: Type IA was the most common pattern seen $(87.5 \%)$ followed by IB $(5.6 \%)$ and IC (2.8\%). One each of types IIA2, IIB and IIC were also seen. Mean length of $162.1 \pm 7.9 \mathrm{~mm}$ was observed from adductor magnus to the bifurcation point of popliteal artery. Conclusion: Type IA was the most common branching pattern seen in this area. However, types IB, IC, IIA2, IIB and IIC were also seen.

Keywords: Anatomical variation, Cross-sectional study, Popliteal artery

Corresponding Author: Reema Kanchan Khalkho, Tutor, Department of Anatomy, RIMS, Ranchi, Jharkhand, India.

E-mail: drreema1980@gmail.com

Received: 05 October 2019

Revised: 11 December 2020

Accepted: 17 December 2019

Published: 22 December 2020

\section{Introduction}

Femoral artery continues obliquely from the osseoaponeurotic opening of adductor magnus to the lower border of popliteus muscle as popliteal artery. It terminates by dividing into anterior and posterior tibial arteries. The branching may be high if it divides at the upper border of the popliteus muscle and "low" if it divides below from the lower border of popliteus muscle. ${ }^{[1]}$ Popliteal artery is the most common artery involved in the aneurysm due to atherosclerosis and in the entrapment syndrome. ${ }^{[2]}$

Variations in branching of popliteal artery is seen as a result of the persistence of segments, abnormal fusion and segmental hypoplasia or aplasia in the lower limb vasculature. It is of 3 types. Type I has normal level of popliteal arterial branching pattern. Type I A has the usual pattern where the anterior tibial artery is the 1st arterial branch, posterior tibioperoneal trunk follows and further bifurcates into posterior tibial and peroneal artery. Type I B is the trifurcation pattern and is seen where the anterior tibial, peroneal and posterior tibial artery arise within $0.5 \mathrm{~cm}$ and there is no tibioperoneal trunk. Type I $\mathrm{C}$ is anterior tibioperoneal trunk pattern. Type II has high division of popliteal artery and has 3 subtypes namely A, B \& C. In Type II A the anterior tibial artery arises at or above the knee joint. In Type II B, the posterior tibial artery arises at or above knee joint. The posterior tibial artery is the 1 st branch which arises above knee joint and has a common trunk for anterior tibial and peroneal arteries. In type IIC, the peroneal artery which is the first branch arises at or above knee joint and has common trunk for anterior tibial artery and posterior tibial artery. In Type III, the branches are hypoplastic/aplastic with altered distal supply. In Type IIIA, the posterior tibial artery is hypoplastic/aplastic. In Type III B, the anterior tibial artery is hypoplastic/ aplastic and the peroneal artery is large. In Type III $\mathrm{C}$, both the anterior tibial artery and posterior tibial artery are hypoplastic/aplastic. [3]

Knowledge of variations of popliteal artery is important for the orthopaedicians, vascular surgeons and radiologists to perform surgical procedures like femoral distal end or proximal tibial or fibular fracture surgery, total knee arthroplasty and especially in surgical interventions performed for Popliteal artery aneurysms or percutaneous vascular reconstruction in the lower extremities. Involvement of variant arteries during surgery may result in complications like transection, fistula formation, pseudoaneurysms and thrombosis. ${ }^{[4]}$ No such study has been conducted in this area. Hence, the present study was proposed.

\section{Aims \& Objectives}

The present study was conducted to assess the anatomical variations in popliteal artery, its terminal branching pattern. 


\section{Subjects and Methods}

Study setting: The present study was conducted at the Department of Anatomy, RIMS, Ranchi, Jharkhand.

Study Design: The present study was cross-sectional in nature.

Study material: The study was conducted upon 36cadavers available for dissection in the department during the study period. Both lower limbs were included and thus a total of 72 lower limbs were studied.

Data collection procedure: Routine dissection instruments, vernier calipers, thread and scale were used for this study. The popliteal fossa was dissected by reflecting the skin, the cutaneous structures, the deep fascia and identifying the boundaries of the popliteal fossa. The popliteal vessels and tibial nerve were exposed. The terminal branches of the popliteal artery, the anterior tibial, posterior tibial arteries and its branch, the peroneal artery were identified and traced along the back of fibula, undercover of flexor hallucis longus. The popliteal artery was exposed in the popliteal fossa and the prevailing pattern of the popliteal artery, its branches and variations were noted.

\section{Data analysis:}

Data was entered in Microsoft Excel and analyzed using SPSS software. Percentage, proportions and contingency tables were used for description of the data. $\mathrm{P}$ value $<0.05$ was considered as statistically significant.

\section{Ethical consideration \& permission:}

Approval from Institutional Ethics Committee was obtained. Confidentiality of records was maintained.

\section{Results}

A total of 72 lower limbs were included in the present study. Table-1 shows the terminal branching pattern of popliteal artery. Type IA was the most common pattern seen (87.5\%) followed by IB (5.6\%) and IC (2.8\%). One each of types IIA2, IIB and IIC were also seen.

[Table 2] shows measurement of popliteal artery from adductor magnus to different points. Mean length of 162.1土 $7.9 \mathrm{~mm}$ was observed from adductor magnus to the bifurcation point of popliteal artery.

\section{Discussion}

Popliteal artery is the continuation of femoral artery beyond osseo-aponeurotic opening of adductor magnus. It is clinically important because of its involvement in knee replacement surgery, vascular surgery and being a common site of

\begin{tabular}{lll}
\hline \multicolumn{3}{|c|}{ Table 1: Showing terminal branching pattern of popliteal artery } \\
\hline $\begin{array}{l}\text { Type } \\
\text { ing }\end{array}$ & of & branch- \\
\hline IA & Frequency & $\%$ \\
IB & 63 & 87.5 \\
\hline IC & 4 & 5.6 \\
\hline IIA1 & 2 & 2.8 \\
\hline IIA2 & 0 & 0 \\
\hline IIB & 1 & 1.4 \\
IIC & 1 & 1.4 \\
IID & 1 & 1.4 \\
IIIA & 0 & 0 \\
IIIB & 0 & 0 \\
\hline IIIC & 0 & 0 \\
\hline
\end{tabular}

\begin{tabular}{|c|c|}
\hline Measurement of popliteal artery & Length (mm) \\
\hline $\begin{array}{l}\text { Adductor hiatus to the bifurcation } \\
\text { point }\end{array}$ & $162.1 \pm 7.9$ \\
\hline $\begin{array}{l}\text { Adductor hiatus to femoral } \\
\text { condyles }\end{array}$ & $133.8 \pm 4.3$ \\
\hline $\begin{array}{l}\text { Adductor hiatus to tibio-peroneal } \\
\text { trunk }\end{array}$ & $3.8 \pm 0.2$ \\
\hline
\end{tabular}

aneurysm. ${ }^{[2]}$ It is a frequent site of variations, the knowledge of which is essential for orthopedicians and radiologists. Arterial reconstruction, transluminal angioplasty, embolectomy and the diagnosis of arterial injury needs proper identification of the variations. Inadequate arterial anastomosis may result in cases which need femorodistal bypass graft. The variations have been described by different authors who studied the same either in the cadavers or in the angiography findings. ${ }^{[4]}$ The present study was conducted to find the anatomical variations of popliteal artery in cadavers.

A total of 72 lower limbs were included in the present study. Type IA was the most common pattern seen (87.5\%) followed by IB $(5.6 \%)$ and IC $(2.8 \%)$. One each of types IIA2, IIB and IIC were also seen. Philipose et al found high termination of Popliteal artery in 2\% of specimens and mid termination of the artery in another $2 \%$ of specimens. They also found termination of Popliteal artery below the lower border of popliteus (below the tibial plateau) in $96 \%$ of individuals. ${ }^{[4]}$ Similar findings were observed by Bettaiah et al who noted that all the specimens belonged to type A pattern where anterior tibial is the first arterial branch; tibioperoneal artery follows and bifurcates into peroneal and posterior tibial. All the terminal branches were at the lower border of the popliteus muscle. ${ }^{[5]}$ On the other hand, Bose et al found that the normal 
level of popliteal arterial branching, of pattern Type IA was observed in $95 \%$ limbs. Normal level of popliteal arterial branching -Trifurcation pattern, type IB was seen in 1limb $(2.5 \%)$. High division of popliteal artery, with anterior tibial artery being the first branch, arising above knee and having a normal course posterior to popliteus muscle, Type IIA1 was also observed in 1 limb $(2.5 \%){ }^{[6]} \mathrm{An}$ other study by Bose et al showed that Type I A was seen in $90 \%$. Type I B pattern was seen in $4 \%$ specimens. Type I C pattern was seen in 1 specimen (2\%). Type 2 A1, Type 2 A2 was not observed in any specimen. Type $2 \mathrm{~B}$ was seen in 1 specimen $(2 \%)$ and Type $2 \mathrm{C}$, was also observed in 1specimen (2\%). Type $3 \mathrm{~A}, 3 \mathrm{~B}, 3 \mathrm{C}$ pattern was not observed in any specimen. ${ }^{[3]}$ Jyothi et al reported that the most frequent pattern being the type $1 \mathrm{~A}$, and the two variations in branching pattern observed being trifurcation (type 1B) in $2 \%$ of specimens and the hypoplasia/absence of the posterior tibial artery (type 3A type) in $10 \%$ of specimens. ${ }^{[7]}$ Singla et al concluded that variations of the popliteal artery were observed in $15 \%$ specimens. ${ }^{8]}$

Measurement of popliteal artery from adductor magnus to different points indicates that the mean length of $162.1 \pm 7.9$ $\mathrm{mm}$ was observed from adductor magnus to the bifurcation point of popliteal artery. Bose et al found that the length of the popliteal artery from the adductor hiatus to the bifurcation point ranged between 126.5 to $188.8 \mathrm{~mm}$ and had a mean value of $151.5 \mathrm{~mm}$. The length of the popliteal artery from the adductor hiatus to femoral condyles ranged between 131.7 to $144 \mathrm{~mm}$ and had a mean value of $136.5 \mathrm{~mm} .{ }^{[3]}$

\section{Conclusion}

It is concluded from the present study that Type IA was the most common branching pattern seen in this area. However, types IB, IC, IIA2, IIB and IIC were also seen.

\section{References}

1. Knee GH, Anatomy G. Elsevier Churchill Livingstone; 2008.
2. Atilla S, E T Ilgıt SA, Yücel C, Talı ET, Işık S. MR imaging and MR angiography in popliteal artery entrapment syndrome. Eur Radiol. 1998;8(6):1025-1029. Available from: https://dx. doi.org/10.1007/s003300050509.

3. Bose E, Ramanathan V. Anatomical variations and morphometric analysis of popliteal artery and its terminal branches in south indian population. IJAR. 2017;5:4388-93. Available from: https://www.researchgate.net/deref/http\%3A//dx.doi. org/10.16965/ijar.2017.346.

4. Philippose S, , Jacinth JS, V M, and. THE ANATOMICAL STUDY OF POPLITEAL ARTERY AND ITS VARIATIONS. Int J Anat Research. 2017;5(4.3):4679-4685. Available from: https://dx.doi.org/10.16965/ijar.2017.435.

5. Bettaiah A, Venkat S, G S. A study of variations in the branching pattern of popliteal artery and its clinical perspective. J Res Med Sci. 2016;1:3584-3589. Available from: https://dx.doi.org/10. 18203/2320-6012.ijrms20162333.

6. Bose E, Ramanathan V, Seshayyan S. An angiographic study in terminal branching pattern of popliteal artery and its clinical connotation. MedPulse - Int J Anatomy. 2018;6:18-22. Available from: https://doi.org/10.26611/1001623.

7. Jyothi S, Vinay S, Pare V. Cadaveric study on anatomical variations of popliteal artery and its terminal branches: a clinical perspective. IJAR. 2019;7:7016-7039. Available from: https://www.researchgate.net/deref/http\%3A//dx.doi.org/ 10.16965/ijar.2019.290.

8. Singla R, Kaushal S, Chabbra U. Popliteal artery branching pattern: a cadaveric study. Eur J Anat. 2012;16:157-62.

Copyright: (C) the author(s), 2020. It is an open-access article distributed under the terms of the Creative Commons Attribution License (CC BY 4.0), which permits authors to retain ownership of the copyright for their content, and allow anyone to download, reuse, reprint, modify, distribute and/or copy the content as long as the original authors and source are cited.

How to cite this article: Khalkho RK, Dubey AK, Prasad R, Lal PK. Study on Anatomical Variations of Popliteal Artery and its Branches. Acad. Anat. Int. 2020;6(2):60-62.

DOI: dx.doi.org/10.21276/aanat.2020.6.2.13

Source of Support: Nil, Conflict of Interest: None declared. 